\title{
Sialolith of the Submandibular Gland: A Case Report
}

\author{
Ferhat Ayranc1 ${ }^{1}$, Mehmet Melih Omezli ${ }^{1}$, Damla Torul ${ }^{1}$, Cagla Sunar ${ }^{1}$, Leyla Koc ${ }^{1}$ \\ ${ }^{1}$ Department of Oral and Maxillofacial Surgery, Faculty of Dentistry, Ordu University, Ordu, Turkey \\ Received: 27 October 2020, Accepted: 09 December 2020, Published online: 31 December 2020 \\ C Ordu University Institute of Health Sciences, Turkey, 2020
}

\begin{abstract}
Sialolithiasis is described as the existence of calcified structures in ducts of salivary glands and is the most widespread disease of the salivary glands. $80-95 \%$ of sialoliths occur at the submandibular salivary gland. Sialoliths with an average frequency of occurrence of 12: 1000 are approximately twice as common in men as in women. Sialoliths may be diagnosed with clinical examination, conventional radiography, computed tomography and ultrasonography. Common clinical signs in cases of sialoliths include painless swelling, large swelling often accompanied by trismus associated with eating, symptoms ranging from moderate discomfort to severe pain. In this case report clinical, radiological signs and surgical therapy of salivary stone in the submandibular gland is represented.
\end{abstract}

Key words: Sialolithiasis, Sialolith, Submandibular gland

Suggested Citation: Ayranci F, Omezli MM, Torul D, Sunar C, Koc L. Sialolith of the Submandibular Gland: A Case Report. Middle Black Sea Journal of Health Science, 2020; 6(2):407-411.

\section{Address for correspondence/reprints:}

Leyla Koç

Telephone number: +90(452 2121283

ORCID-ID 0000-0001-8170-3872

E-mail: lakrimaleyla55@gmail.com

DOI: $10.19127 /$ mbsjohs.817042

\section{Introduction}

Sialolithiasis is described as the existence of calcified structures in ducts of salivary glands and is the most widespread disease of the salivary glands (Angiero et al., 2008; Iqbal, Gupta et al. 2012). The size of sialoliths is generally $1-10 \mathrm{~mm}$, they are seldom observed to be bigger than $15 \mathrm{~mm}$ (Fowell and MacBean, 2012; Sadıkhov et al., 2019). Although sialoliths are more common in the adult population, cases of sialolith have also been reported in children in the literature. Sialoliths with an average frequency of occurrence of 12: 1000 are approximately twice as common in men as in women (Iqbal et al., 2012). While $80-95 \%$ of salivary stones seen in the submandibular gland, are seen in the $5-20 \%$ parotid gland, $1-2 \%$ in the sublingual and minor salivary glands (Iqbal et al., 2012). Sialoliths are clinically usually characterized by pain and swelling. There are also symptoms such as reduced saliva flow in the mouth of the salivary gland ducts, restriction of the mouth opening and pus flow (Omezli et al., 2016). 
While $80 \%$ of sialoliths cases can be detected by simple radiographic methods, it may be necessary to examine the other $20 \%$ by imaging techniques like computed tomography, magnetic resonance imaging (MRI), ultrasonography, sialography or sialendoscopy (Pastor-Ramos et al., 2014). Conservative methods can be applied for the treatment of small size sialoliths (Aiyekomogbon et al., 2018). Conservative treatment methods are antibiotics, anti-inflammatory drugs, local massage and heat application to the salivary gland, spontaneous passage from the salivary gland duct with saliva flow stimulants (Marchal and Dulguerov, 2003; Aiyekomogbon et al., 2018). When cannot achieved with conservative methods, recently interventional methods with minimally invasive techniques are applied. These are stone removal from the duct ostium with a blunt instrument, interventional sialography, therapeutic sialendoscopy, extracorporeal shock wave lithotripsy (ESWL), CO2, holmium and erbium: YAG laser application, intraductal lithotripsy and piezoelectric surgery (Angiero et al., 2008; Pastor-Ramos et al., 2014; Kondo et al., 2018; Guenzel et al., 2019).

In this case report clinical, radiological signs and surgical therapy of salivary stone in the submandibular gland is represented.

\section{Case}

A 40-year-old male patient was admitted to Ordu University, Faculty of Dentistry, Department of Oral and Maxillofacial Surgery for complaints of swelling and pain during eating in the left submandibular area. Also, he had swelling, tension and sensitivity in the left submandibular area. The patient had no significant systemic disease. Radiographic examination showed sialolith in the left submandibular area (Figure 1-2). After the informed consent obtained, Under the regional anesthesia sialolith was surgically removed with an intraoral approach. An incision was made on the submandibular gland duct where the sialolith is located. The sialolith was attentively removed from the base of the mouth, preserving the submandibular salivary gland by blunt dissection. Excised sialolith was $16 \mathrm{~mm} \times 8 \mathrm{~mm}$ in size, hard structure and yellow in color (Figure 3). After the sialolith was removed, a drainage catheter was placed in the submandibular gland duct (Figure 4). Postoperatively, the patient was prescribed antibiotic (Amoxicillin clavulanate, 2000 mg / day), analgesic (Naproxen sodium) and Orohex mouthwash. The drainage catheter was removed after 48 hours. No complications were observed on the 7th postoperative day. A clear saliva flow was observed from the left submandibular gland duct. No recurrence was observed after 1 year of follow-up.

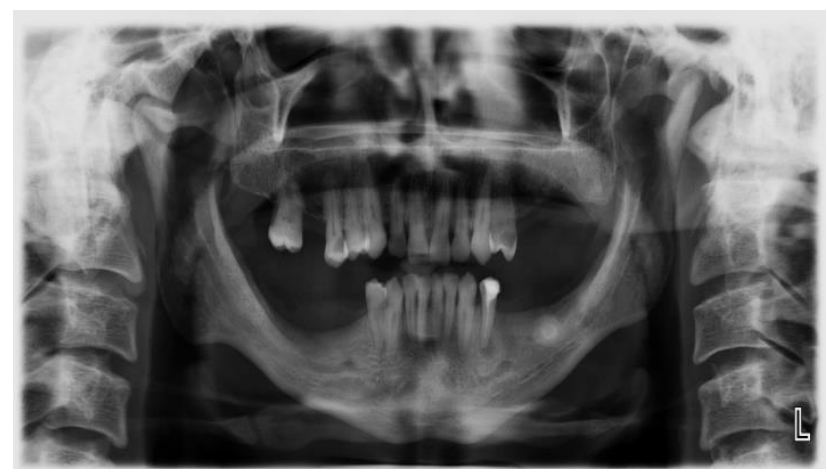

Figure 1. Preoperative panoramic radiography

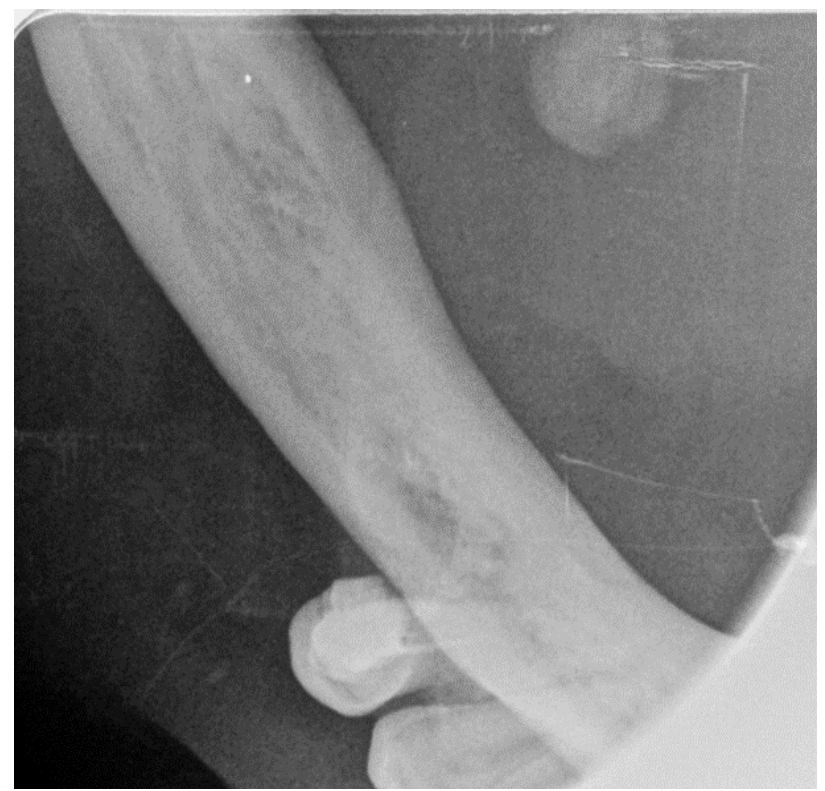

Figure 2. Preoperative occlusal radiography

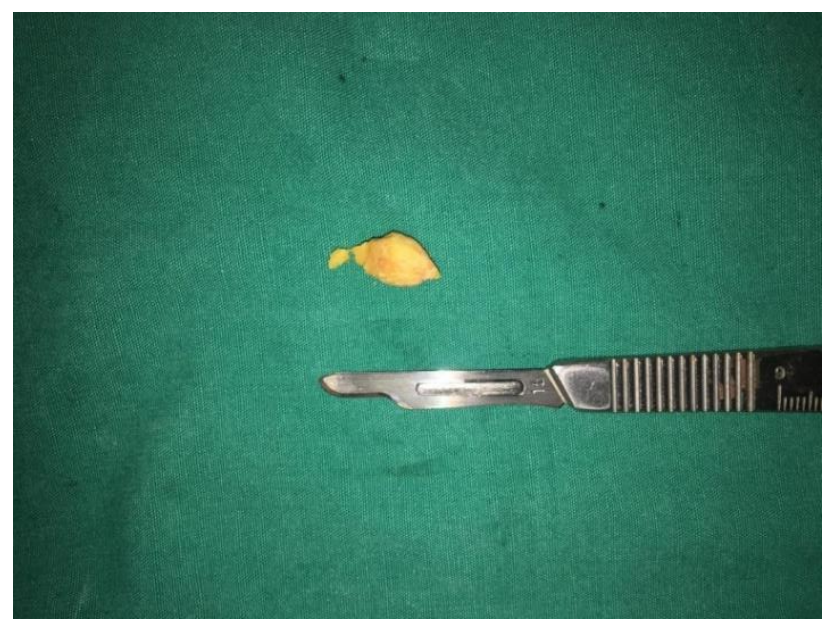

Figure 3. Excised sialolith 


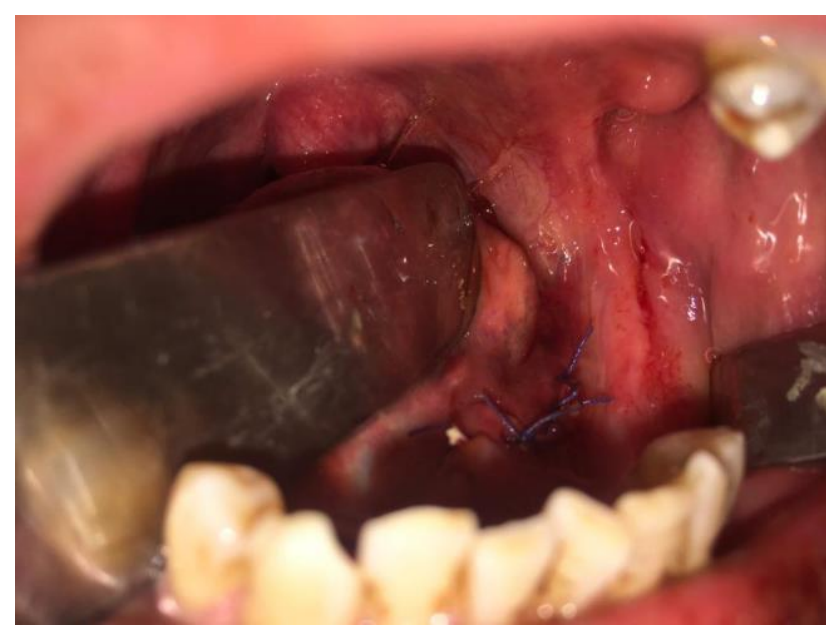

Figure 4. Postoperative intraoral view

\section{Discussion}

Sialolithiasis is described as the existence of calcified structures in ducts of salivary glands and is the most widespread disease of the salivary glands.(Angiero et al., 2008; Iqbal et al., 2012) It has also been shown that stagnation in saliva flow, infection of the salivary duct or gland, physical damage to the salivary duct or gland can predispose to stone genesis. (Sunder et al., 2014) Recently, effects of tobacco on saliva have also been examined and it has been shown that tobacco smoking increases the cytotoxic efficiency of saliva, decreases the polymorphonuclear phagocytic capability, reduces salivary amylase, peroxidase and these can cause stone formation.(Aiyekomogbon et al., 2018) A study has shown a relationship between sialolithiasis and nephrolithiasis however, it was stated that more researches are required verify this relationship.(Wu Hung et al., 2016) Sialoliths appear mostly in the submandibular gland.(Iqbal et al,. 2012) The higher alkali and calcium concentration of the saliva produced by the submandibular gland, the long and curved anatomical structure of the submandibular gland duct, the occurrence of saliva flow against gravity are effective in increasing the incidence of sialoliths in the submandibular gland.(Oliveira et al., 2016)

Sialoliths seen in the submandibular salivary gland may be easily diagnosed as they show evident clinical features, also they may remain completely asymptomatic.(Sunder et al., 2014) Common clinical signs in cases of sialoliths include painless swelling, large swelling often accompanied by trismus associated with eating, symptoms ranging from moderate discomfort to severe pain.(Sunder et al., 2014) The clinical symptoms observed in our case are consistent with the literature.
Ultrasonography is recommended as the first imaging option in cases suggesting the presence of sialolith clinically (Aydin et al., 2004). Advantages of ultrasonography include low cost, noninvasive technique and no radiation exposure to the patient. Other imaging techniques include panoramic and occlusal radiographs, computed tomography, ultrasonography, sialography, magnetic resonance imaging or sialendoscopy (Pastor-Ramos et al., 2014). Occlusal radiography is the most dependable technique for imaging submandibular sialolith. However, since the imaging area is up to the second molar tooth posteriorly, it is not reliable for the diagnosis of giant sialoliths occuring in the posterior area of the Wharton duct (Rai and Burman, 2009). In our case, diagnosis of sialolith was made by panoramic and occlusal radiographs. Digital sialography had arisen the susceptibility and specificity of the traditional sialography technique. The main benefit of this new technique is to obtain a clear view of the anatomical structures without superposition. It is a disadvantage that the conventional sialography method requires the use of contrast material. Contrast agents can expose the patient to radiation dangers, perforate the wall of the salivary gland duct, reason pain and contraindicated in case of acute infection (Sunder et al., 2014). The sialo-MRI is a non-invasive technique used in the evaluation of salivary gland diseases, a method introduced recently. Among the most important advantages of this technique are the absence of contrast agent injection, its ability to produce sialographic images without ionizing radiation and the unchanged structural anatomy of the salivary glands. But the main disadvantages are requiring long time, being expensive, lack of compliance in claustrophobic patients and the artifact formation in those with metallic dental prostheses (Andretta et al., 2005).

Treatment of sialolith depends on the duration of symptoms, the number of recurrences, the size and localization of the sialolith. Lustmann et al. reported that symptomatic sialoliths must be treated with an intraoral surgical approach (Lustmann et al., 1990; Ozdede et al., 2016). If there is no infection, sialoliths can be removed by hand manipulation, which are located near to the orifice of Wharton's duct. Surgical excision of sialoliths is suggested, if located on the distal side of the Wharton duct and in front of the lower first molar with respect to the duct. Recently, interventional radiological methods such as ESWL (Extracorporeal shortwave lithotripsy), which is a safe, effective, minimally invasive technique for salivary stones, are becoming increasingly popular 
(Aiyekomogbon et al., 2018). Today, laser methods such as $\mathrm{CO} 2$ and Erbium: YAG are also used in sialolith treatment (Haas et al., 2018). Treatment methods such as ESWL and sialendoscopy are efficient alternatives to traditional surgical methods for small salivary stones. Methods like sialoadenectomy are invasive techniques and may damage many significant tissues, particularly the marginal mandibular, lingual nerve and hypoglossal nerve. The formation of new cells and easier proliferation of cells in laser applied tissues provides an increase in wound healing quality. Thanks to these features of the laser minimal swelling, bleeding and pain are observed after surgery (Angiero et al., 2008; Haas et al., 2018).

Piezoelectric surgery is used to remove sialoliths (Pastor-Ramos et al., 2014). Piezoelectric surgery technique is a minimally invasive technique that reduces damage to surrounding soft tissues (PastorRamos et al., 2014) The limitation of this technique is that it is dependent on the accessibility of the stone (Pastor-Ramos et al., 2014).

\section{Conclusion}

In conclusion, sialoliths should be evaluated with preoperative history, clinical examination findings and accurate imaging methods. Localization of salivary stone is also important in diagnosis and treatment approaches. It should be distinguished from soft tissue calcifications such as calcified lymph nodes and vascular calcifications, bone lesions such as mandibular torus and osteoma.

Ethics Committee Approval: Approval was received for this study from the patient.

Peer-review: Externally peer-reviewed.

Author Contributions: Concept- T.D., K.L.; Design- K.L., S.C.; Funding- A.F., T.D., S.C.; Materials- O.M.M., A.F.; Data Collection/Data Process- O.M.M., A.F., T.D.; Analyze or CommentO.M.M., A.F., T.D.; Literature Scanning- T.D., S.C., K.L.; Writer of Paper- T.D., S.C., K.L.

Conflict of Interest: No conflict of interest was declared by the authors.

Financial Disclosure: The authors declared that this study hasn't received no financial support.

\section{References}

Aiyekomogbon JO, Babatunde LB, Salam AJ. Submandibular sialolithiasis: the roles of radiology in its diagnosis and treatment. Ann Afr Med 2018; 17(4): 221.

Andretta M, Tregnaghi A, Prosenikliev V, Staffieri A. Current opinions in sialolithiasis diagnosis and treatment. Acta Otorhinolaryngol Ital 2005; 25(3): 145-149.

Angiero F, Benedicenti S, Romanos GE, Crippa R. Sialolithiasis of the submandibular salivary gland treated with the 810-to 830-nm diode laser. Photomed Laser Surg 2008; 26(6): 517-521.

Aydın U, Yesildag A, Bayar O, Gulsoy U. Diagnostic Imaging of Submandibular Sialolith-Case Series. Acta Odontologica Turcica. 2004; 21(1): 47-52.

Fowell C, MacBean A. Giant salivary calculi of the submandibular gland. J Surg Case Rep 2012; 2012(9): 6-6.

Guenzel T, Hoch S, Heinze N, Wilhelm T, Gueldner C, Franzen A, Coordes A, Lieder A, Wiegand S. Sialendoscopy plus laser lithotripsy in sialolithiasis of the submandibular gland in 64 patients: A simple and safe procedure. Auris Nasus Larynx 2019; 46(5): 797-802.

Haas OL, Scolari N, L da Silva Meirelles, Favoretto AX, de Oliveira RB. Sialolith removal in the submandibular region using surgical diode laser: Report of two cases and literature review. Oral Maxillofac Surg 2018; 22(1): 105-111.

Iqbal A, Gupta AK, Natu SS, Gupta AK. Unusually large sialolith of Wharton's duct. Ann Maxillofac Surg 2012; 2(1): 70.

Kondo N, Yoshihara T, Yamamura Y, Kusama K, Sakitani E, Seo Y, Tachikawa M, Kujirai K, Ono E, Maeda Y. Treatment outcomes of sialendoscopy for submandibular gland sialolithiasis: The minor axis of the sialolith is a regulative factor for the removal of sialoliths in the hilum of the submandibular gland using sialendoscopy alone. Auris Nasus Larynx 2018; 45(4): 772-776.

Lustmann J,Regev E, Melamed Y. Sialolithiasis: a survey on 245 patients and a review of the literature. International J Oral Maxillofac Surg 1990; 19(3): 135-138.

Marchal F, Dulguerov P. Sialolithiasis management: the state of the art. Arch Otolaryngol Head Neck Surg 2003; 129(9): 951-956. 
Oliveira TdP, Oliveira INF, Pinheiro ECP, Gomes RCF, Mainenti P. Giant sialolith of submandibular gland duct treated by excision and ductal repair: A case report. Braz J Otorhinolaryngol 2016; 82(1): 112-115.

Omezli M, Ayranci F, Sadik E, Polat M. Case report of giant sialolith (megalith) of the Wharton's duct. Niger J Clin Pract 2016; 19(3): 414-417.

Ozdede M, Haciosmanoglu N, Kaya E, Ozer H, Akin E, Seckin A, Rzayev S. Sialolit: Sialolith: assessment of 3 cases with clinical, radiographic and ultrasonographic findings. Acta Odonto Turc 2016; 33(1)35-8

Pastor-Ramos V, Cuervo-Díaz A, Aracil-Kessler L. Sialolithiasis. Proposal for a new minimally invasive procedure: Piezoelectric surgery. J Clin Exp Dent 2014; 6(3): e295.

Rai M, Burman R. Giant submandibular sialolith of remarkable size in the comma area of Wharton's duct: a case report. J Oral Maxillofac Surg 2009;67(6): 1329-1332.

Sadıkhov M, Kahraman Ş, Yücel ZE. Giant submandibular gland duct sialolith: A case report. BSJ Health Sci 2019; 2(3): 74-77.

Sunder VS, Chakravarthy C, Mikkilinine R,Mahoorkar S. Multiple bilateral submandibular gland sialolithiasis. Niger J Clin Pract 2014; 17(1): 115-118.

Wu CC, Hung SH, Lin HC, Lee CZ, Lee HC, Chung SD. Sialolithiasis is associated with nephrolithiasis: a case-control study. Acta Otolaryngol 2016; 136(5): 497-500. 